\title{
A Review of Glass Fibre Recycling Technology Using Chemical and Mechanical Separation of Surface Sizing Agents
}

\author{
Jih-Hsing Chang (D), Ya-Shiuan Tsai and Pei-Yu Yang * \\ Department of Environmental Engineering and Management, Chaoyang University of Technology, \\ Taichung 413310, Taiwan; changih@cyut.edu.tw (J.-H.C.); angeange97971@gmail.com (Y.-S.T.) \\ * Correspondence: pyyang@cyut.edu.tw; Tel.: +886-4-2332-3000
}

Citation: Chang, J.-H.; Tsai, Y.-S.; Yang, P.-Y. A Review of Glass Fibre Recycling Technology Using Chemical and Mechanical Separation of Surface Sizing Agents. Recycling 2021, 6, 79. https://doi.org/10.3390/ recycling6040079

Academic Editor: Michele John

Received: 30 July 2021

Accepted: 23 November 2021

Published: 2 December 2021

Publisher's Note: MDPI stays neutral with regard to jurisdictional claims in published maps and institutional affiliations.

Copyright: (c) 2021 by the authors. Licensee MDPI, Basel, Switzerland. This article is an open access article distributed under the terms and conditions of the Creative Commons Attribution (CC BY) license (https:// creativecommons.org/licenses/by/ $4.0 /)$.

\begin{abstract}
Glass fiber is widely used in various modern industrial applications because it has the advantages of good electrical insulation performance and good process ability. Inevitably, some flawed glass fiber generated during manufacturing processes becomes waste and, in recent years, the treatment or recycling of glass fiber waste has become an environmental concern. Since glass fiber is brittle, non-wearing, and can easily generate static electricity after friction, the surface of glass fiber must be coated with a wetting agent (i.e., surface sizing agent) to overcome these disadvantages. However, glass fiber waste cannot be directly recycled as glass raw materials due to the presence of the surface sizing agent and the high content of sodium element. Therefore, there is a need to develop a feasible technology for removal of surface sizing agent in order to recycle glass fiber waste. In this study, two methods were used to remove surface sizing agent from glass fiber waste. After removing the surface sizing agent, the treated glass fiber waste can replace sand particles for manufacturing controlled low-strength material (CLSM). The first method for removing surface sizing agent used different organic solvents such as ethyl acetate to dissolve the surface coating (i.e., surface sizing agent). Then, an optical microscope was used to observe the surface changes before and after such removal treatments. The second method involved grinding glass fiber waste into a fine powder and heating it to a high temperature. An X-ray diffractometer (XRD) and X-ray fluorescence (XRF) were used to analyze the surface characteristics of the glass fiber waste. The experimental results showed that different organic solvents could not effectively remove the surface sizing agent, even if the glass fiber waste was processed by ultrasonic vibration for $5 \mathrm{~h}$. In contrast, after high heating at $800{ }^{\circ} \mathrm{C}$ for $2 \mathrm{~h}$, the surface sizing agent could be removed, and glass fiber waste transformed to cristobalite. The CLSM concrete produced by mixing cristobalite with cement in an appropriate proportion can meet the CLSM specification standard in Taiwan.
\end{abstract}

Keywords: CLSM; glass fiber waste; recycled technology; surface sizing agent

\section{Introduction}

Glass fiber is widely used in various modern industrial applications. Its application advantages include the following: corrosion resistance, high temperature resistance, low moisture absorption, good electrical insulation, non-perishable, and high chemical stability, as well as it can be used in various processing procedures [1]. However, because glass fiber is brittle, easy to break, and not wear resistant, there are still certain limitations in its application. In addition, static electricity is easily generated after friction, which limits industrial applications. In order to meet industry standards, silane coupling agents (i.e., surface sizing agents) are widely used to increase the strength of the substrate and fiber interface, that is, the strength of the glass fiber is enhanced by forming a polymer composite material on the glass fiber [2]. In the process of manufacturing glass fiber, a specific procedure is designed to coat the surface of the glass fiber with a surface sizing agent [3]. The ductility facilitates processing, such as fiber weaving. [4]. Inevitably, used glass fibers will eventually become waste during the product life cycle. Therefore, for 
decades, the treatment or recycling of glass fiber waste has been an important issue in environmental engineering [5].

During the manufacturing process, 10 15\% of the total amount of glass fiber becomes waste materials. The shape of glass fiber waste is a disorderly and filamentous and its surface layer contains surface sizing agents such as epoxy resin, polyvinyl alcohol, starch, wax and silane. The complex characteristics of glass fiber such as high flexibility, disordered shapes, and complicated chemical coatings always make it difficult to recycle. For instance, glass raw materials should be melted for drawing processes to fabricate the very small diameter (from 0.05 to 0.2 times of hair) of a single glass fiber; however, glass fibers covered with sizing agent cannot be completely melted, which results in the failure of glass fiber recycling. In addition, concrete with mixing glass fiber waste leads to very low compressive strength due to the chemical coating with low attachment ability [4]. As a result, glass fiber waste is currently treated by solidification, stabilization, or heat treatment techniques. In practice, glass fiber waste is usually treated by mixing it with soil for landfills [6]. Such treatment needs abundant land resources for burying glass fiber waste. Since land is a very critical and rare resource not only to the ecosystem but also economics in Taiwan, the deep burial method is no longer feasible.

One successful case about recycling pure glass fiber waste without sizing agent has been reported $[7,8]$. This recycling process could generate value-added materials by mixing with cements. This technology has already converted 250,000 ton/year of discarded glass fiber waste into beneficial use applications in the concrete construction industry. In this process, glass fiber waste is ground to a fine powder that effectively functions as a reactive pozzolanic admixture for use in Portland cement-based building materials and products. Such reactive pozzolanic admixture is especially suited for white concrete applications. According to the above illustration, glass fiber waste possesses a high potential for recycling if the sizing agent on the surface can be removed. Hence, there is a need for a removal technique with market value for the recycled glass fiber waste.

In order to effectively recycle glass fiber waste, an innovative technique to remove the surface sizing agent is the key recycling procedure. In this study, the removal techniques that were evaluated included: (1) removal of sizing agent by organic solvents and (2) removal of sizing agent by heating process. Afterwards, the treated glass fiber waste was used to replace sand to build CLSM (controlled low-strength material, CLSM) concrete. A controlled low-strength material (CLSM) concrete is usually constructed using cement, sand, recycled waste, and water. The properties of CLSM concrete include compressive strength, subsidence, permeability, and re-excavation. Among them, the most important property is the compressive strength for practical applications. According to the industry specification standard of CLSM concrete in Taiwan, its compressive strength should reach $84 \mathrm{kgf} / \mathrm{cm}^{2}$. The focus of this study is to create a feasible technology for removing the sizing agent from the outer layer of glass fiber waste and to recycle the glass fiber waste into CLSM concrete.

\section{Materials and Methods}

The experimental samples of glass fiber waste were collected from a certain waste site located in the central region of Taiwan. The surface of the glass fiber waste was covered with some kinds of sizing agent. Three experimental processes were conducted including: 1. removal of sizing agent by organic solvents, 2 . removal of sizing agent by heating process, and 3. CLSM concrete constructed with treated glass fiber waste. The reasons why we chose glass fiber waste to replace sand in the CLSM concrete include: 1 . the main chemical component is silica dioxide, which is the same as that in sand, 2. the glass fiber waste can play the gradation role during the solidification function with cements.

\subsection{Removal of Sizing Agent by Organic Solvents}

Ethyl acetate and toluene were used to remove the surface sizing agent. First, $45 \mathrm{~g}$ of the sample were soaked in $500 \mathrm{~mL}$ of organic solvent at room temperature for $30 \mathrm{~min}$. Then, 
the sample was processed by ultrasonic vibration for $5 \mathrm{~h}$. During the ultrasonic vibration, the surface structure of the sample was observed with a $400 \times$ optical microscope every hour, and an X-ray diffractometer (Rigaku, MiniFlex, Tokyo, Japan) was used to analyze the sample to evaluate the removal of the surface sizing agent.

\subsection{Removal of Sizing Agent by Heating Process}

In order to remove the surface treatment agent, a heat treatment method can also be used, in which the glass fiber waste is cured in hot air (from $450{ }^{\circ} \mathrm{C}$ to $550^{\circ} \mathrm{C}$ ) or heated in an oxygen-free environment (i.e., pyrolysis) $[9,10]$. The filaments of glass fiber waste were crushed into fine powders by a hammer-crushing device, then, the samples were heated in the furnace at $500,600,700$, or $800^{\circ} \mathrm{C}$ for $2 \mathrm{~h}$. Afterwards, each sample, under different temperatures, formed a block. This block was crushed to powder and observed by the same optical microscope to clarify the removal of surface sizing agent. In addition, an X-ray diffraction instrument (Rigaku, MiniFlex, Tokyo, Japan) was applied to analyze the samples and gain insights into the lattice of the treated glass fiber waste.

\subsection{CLSM Concrete Constructed with Treated Glass Fiber Waste}

According to the ASTM C109 method, the mixing ratio of cement to sand is 1:2.75. In this study, the sand in the concrete were completely replaced by the treated sample. In the beginning of constructing the concrete, the inner layer of the mold was coated with lubricant. Then, the mixed slurry (treated glass fiber waste, cement, and water) was poured into the mold two times (each layer was about $2.5 \mathrm{~cm}$ ). Then, the slurry was guided 32 times with a rod and finally scraped off the excess slurry outside the mold. The mold was placed in a constant temperature and humidity box. After $24 \mathrm{~h}$, the concrete sample was removed from the mold and cured for 7 days. At last, the compressive strength of the sample $\left(\mathrm{kgf} / \mathrm{cm}^{2}\right)$ was determined.

\section{Results}

Figure 1 shows the microscopic images of glass fiber waste under different solvent treatments. By comparing Figure 1a,b, it can be seen that there is a distinct layer coated on the glass fiber and this coated layer possesses minor damage by ethyl acetate under ultrasonic for $5 \mathrm{~h}$. The ethyl acetate tests (data not shown here) of various treated hours present similar phenomena to Figure $1 \mathrm{~b}$. In addition to the incomplete removal of surface sizing agent from the glass fiber waste, the procedures with organic solvents consume a relatively long time. Moreover, such a technique yields another liquid waste (i.e., used organic solvents) that also need to be effectively treated. Taking the above into consideration, the removal efficiency of solvent technique is not effective. Likewise, the same conclusion pertaining to toluene solvent can be drawn by comparing Figure 1a,c. In Figure 1c, some irregular obstructive can be observed. Figure $1 \mathrm{~d}$ shows the XRD spectrum of using organic solvents to remove sizing agent and Figure 1e shows the original waste glass fiber XRD spectrum. By comparing the two, the effect is not obvious.

As the glass fiber waste (without grinding) is heated at $800{ }^{\circ} \mathrm{C}$ for $2 \mathrm{~h}$, the surface sizing agent is carbonized (shown in Figure 2a). In contrast, a lump occur (as shown in Figure $2 \mathrm{~b}$ ) as the glass fiber waste (with grinding) is heated at $800^{\circ} \mathrm{C}$ for $2 \mathrm{~h}$. The lump also appears even when the sample is heated at 500,600 , and $700{ }^{\circ} \mathrm{C}$ (data not shown here). This implies that the grinding procedure is beneficial to the removal of surface sizing agent and the lattice transformation of the silicate. Figure 2c,d shows the XRD spectrum of glass fiber waste with and without heating treatment, respectively. By comparing Figure $2 c, d$, it can be observed that a large amount of high-purity cristobalite was produced after the heating process. This cristobalite material may possess high potential as a recycling material to replace sand for CLSM concrete. 

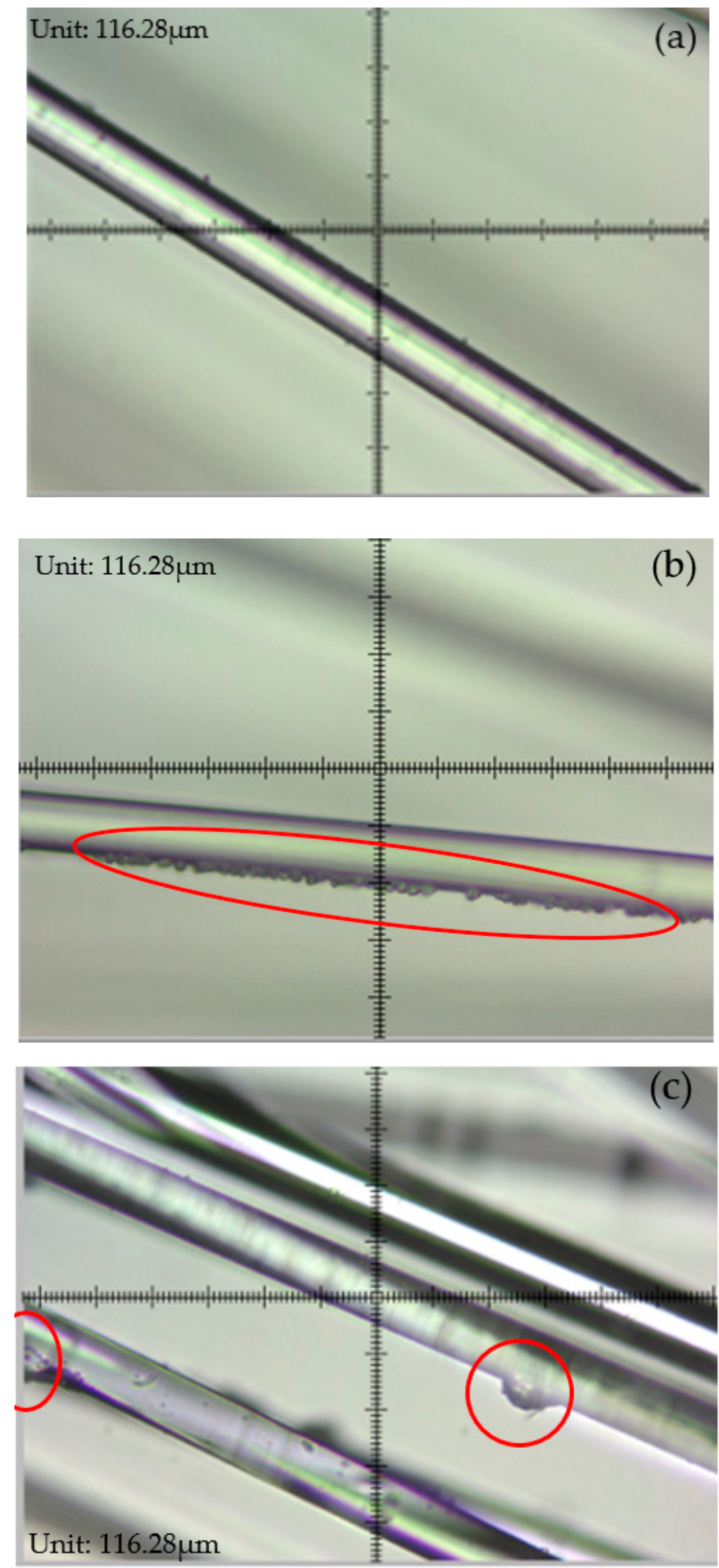

Figure 1. Cont. 

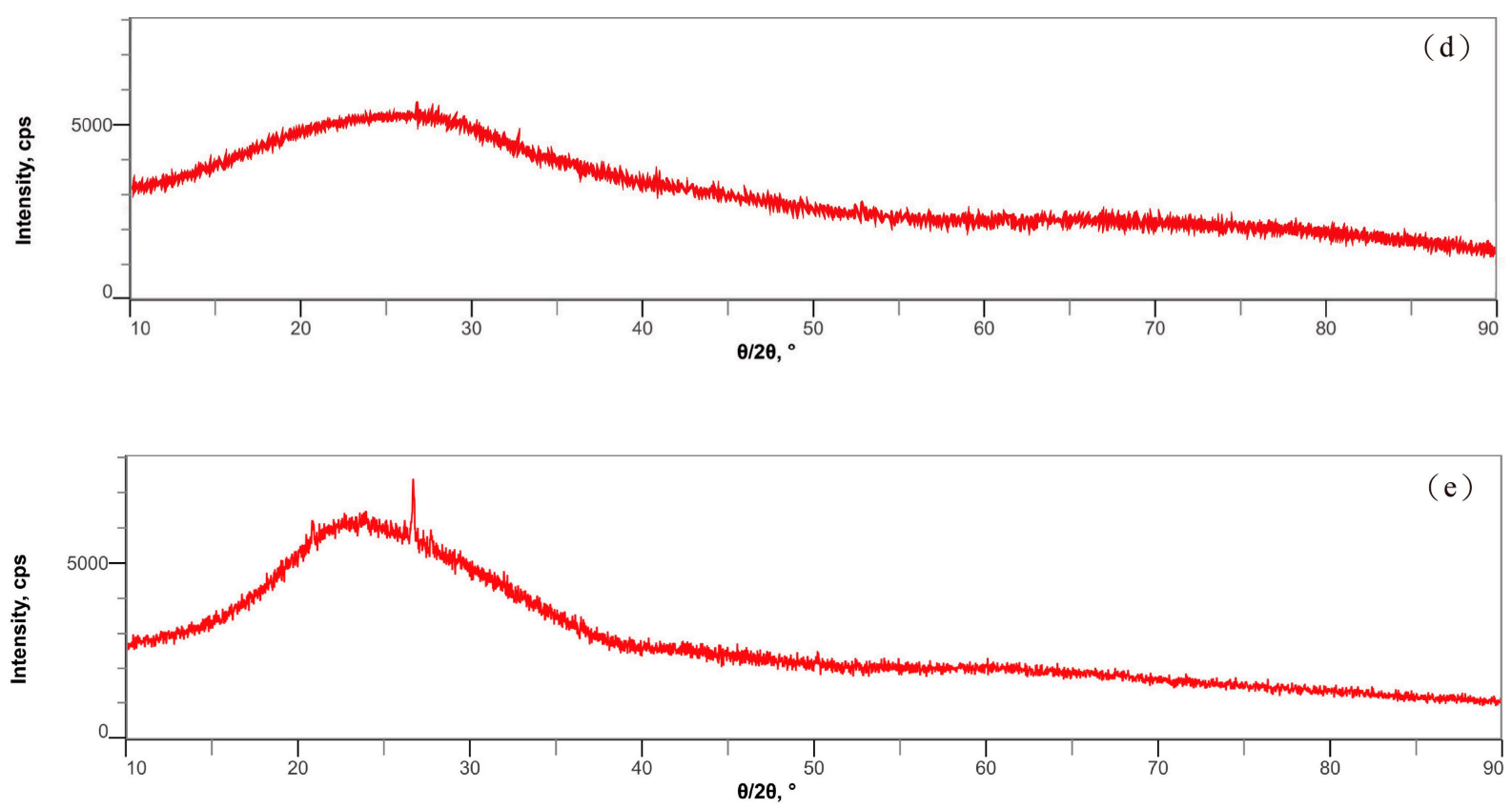

Figure 1. The characteristics of glass fiber waste removed by organic solvents: (a) Original glass fiber waste; (b) treated by ethyl acetate under ultrasonic for $5 \mathrm{~h}$; (c) treated by toluene under ultrasonic for $5 \mathrm{~h}$; (d) XRD spectrum of glass fiber waste treated by organic solvent; (e) XRD spectrum of glass fiber waste.

Figure 3 shows the images of concrete samples under different situations. Concretes No. 1 and No. 2 are made of the cement mixed with sand and heated glass fiber, respectively. The organic solvent method cannot remove the surface sizing agent on the outer layer of the waste glass fiber. The removal efficiency of surface sizing agent using organic solvent method is not good and the time for processing is too long. In addition to judging by microscope, it is also judged by XRD spectrum. If it is made into cement, it will crack and not agglomerate. Figure $3 \mathrm{a}, \mathrm{b}$ shows that concrete No. 2 has a white color, which may be due to the cristobalite. It can be observed that the surface of concrete No. 2 looks smoother than concrete No. 1, which can be attributed to the fine particle size of the cristobalite. By comparing Figure $3 c, d$, concrete No. 2 seems to remain intact, and fails the compressive test at a lower load as compared with concrete No. 1. In addition, Table 1 lists the compressed strength of different concrete samples. From Table 1, the compressive strength values of concretes No. 1 and No. 2 are 269.44 and $226.28 \mathrm{kgf} / \mathrm{cm}^{2}$, respectively. The compressive strength of concrete No. 2 is only $16 \%$ lower than that of concrete No. 1. Such compressive strength of concrete No. 2 still reaches the regular structure criteria. Apparently, its compressive strength is much higher than the CLSM industry specification of $84 \mathrm{kgf} / \mathrm{cm}^{2}$ for drainage roads, irrigation ditches, or for unreinforced concrete structures. Because the cost of sand, treatment income of glass fiber waste, transport fee, and thermal operation cost is around 15,100,50, and 30 USD per ton, respectively, the recycling profit is around 35 USD per ton (i.e., $15+100-5-30=35$ ).

Table 1. Compressive strength of different concrete samples.

\begin{tabular}{lcc}
\hline \multicolumn{1}{c}{ Test Item } & No. 1 & No. 2 \\
\hline Cross surface area $\left(\mathrm{cm}^{2}\right)$ & 25 & 25 \\
\hline Maximal loading $(\mathrm{kg})$ & 6736 & 5657 \\
\hline Compressed strength $\left(\mathrm{kgf} / \mathrm{cm}^{2}\right)$ & 269.44 & 226.28 \\
\hline
\end{tabular}



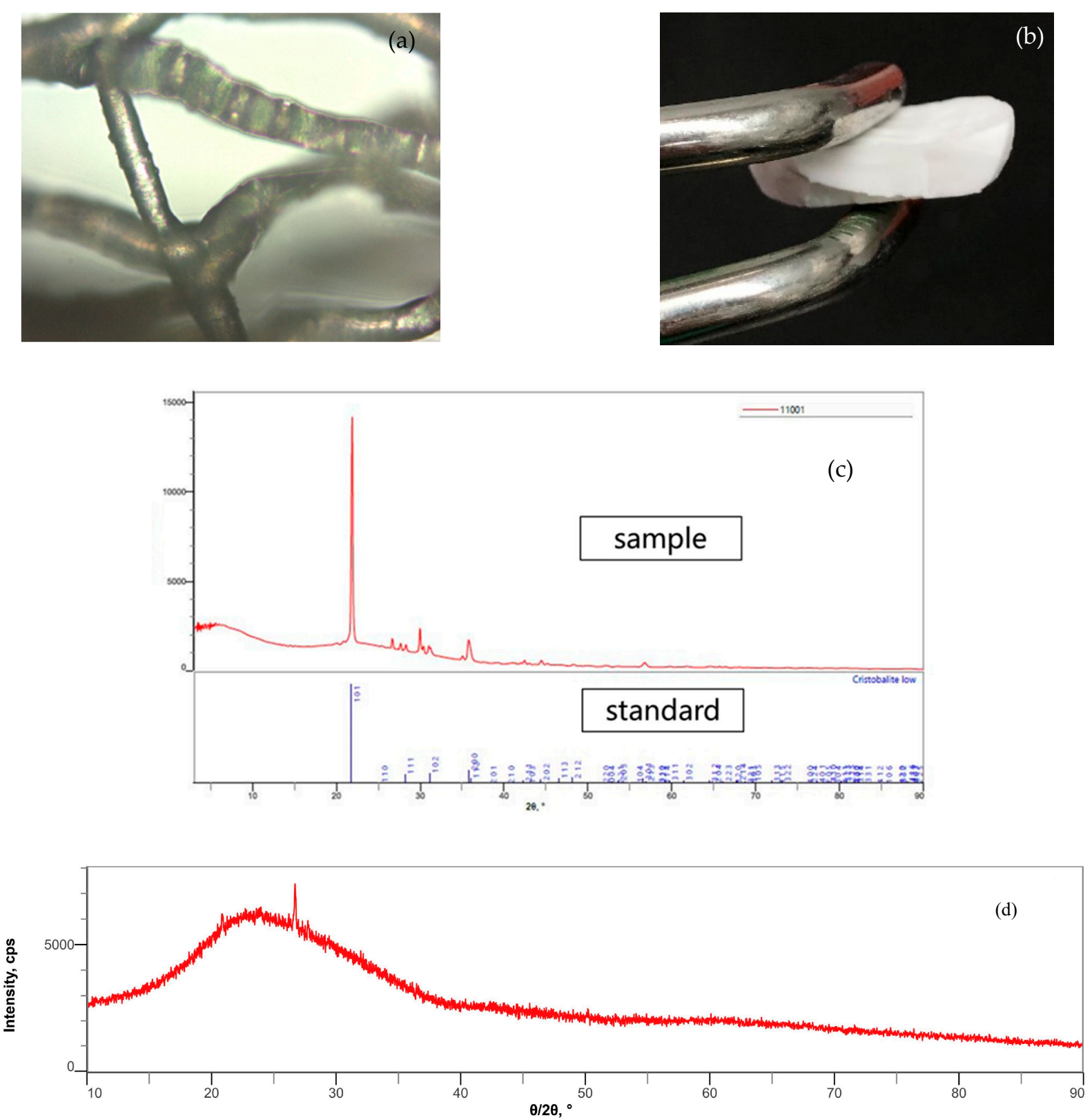

Figure 2. The characteristics of glass fiber waste with and without heating treatment: (a) The image of sample (without grinding) heated at $800^{\circ} \mathrm{C}$ for $2 \mathrm{~h}$; (b) the image of sample (with grinding) heated at $800{ }^{\circ} \mathrm{C}$ for $2 \mathrm{~h}$; (c) XRD spectrum of glass fiber waste heated at $800{ }^{\circ} \mathrm{C}$ for $2 \mathrm{~h}$; (d) XRD spectrum of glass fiber waste without heating treatment. 

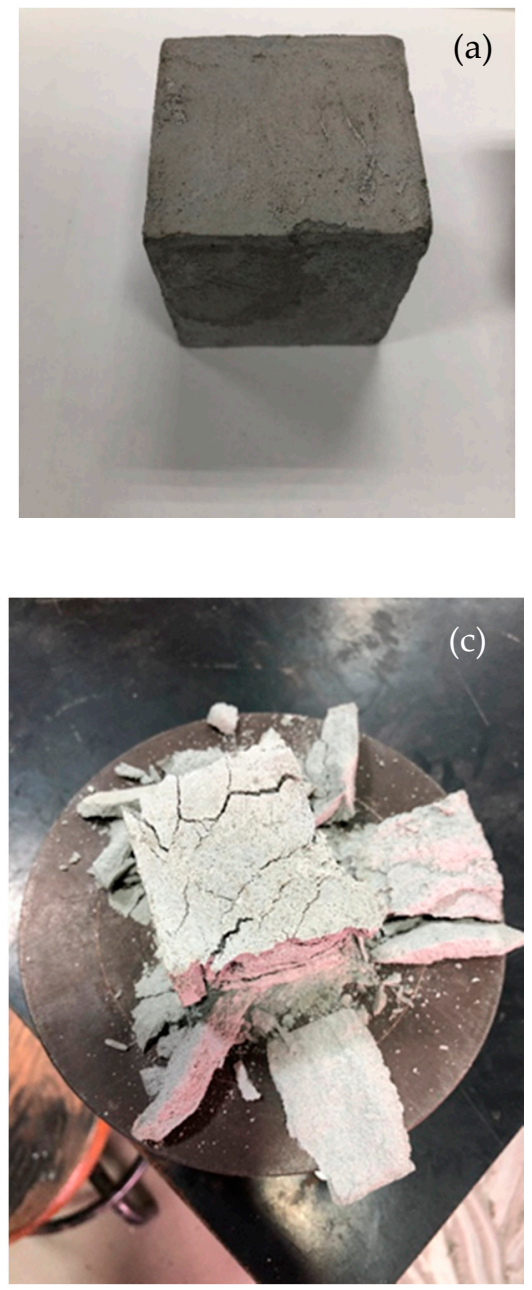
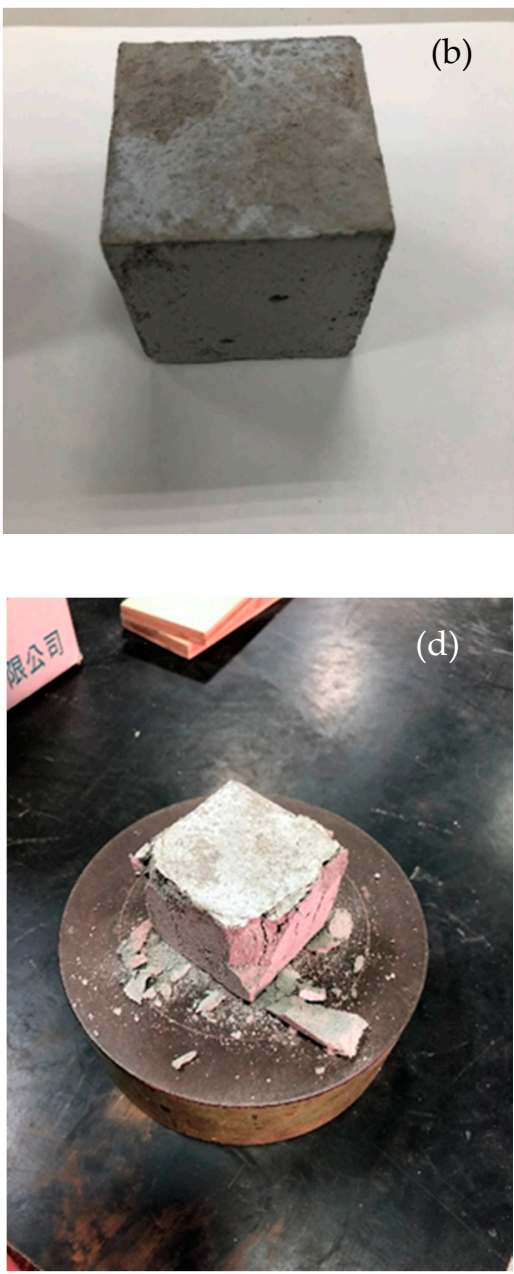

Figure 3. The images of concrete samples under different situations: (a) Concrete No. 1 made of cement and sand; (b) concrete No. 2 made of cement and heated glass fiber waste; (c) compressive test of concrete No. 1; (d) compressive test of concrete No. 2.

\section{Conclusions}

1. After five-hour dissolution, neither ethyl acetate nor toluene can effectively remove the surface sizing agent of glass fiber waste.

2. During the heating process, the grinding procedure is beneficial to the removal of surface sizing agent and the lattice transformation of the silicate.

3. A high-purity silica structure (i.e., cristobalite) can be obtained through the grinding and heating processes of glass fiber waste.

4. The compressive strength of CLSM concrete produced by mixing cristobalite with cement in an appropriate proportion is much higher than the CLSM industry specification standard $\left(84 \mathrm{kgf} / \mathrm{cm}^{2}\right)$.

5. The glass fiber waste after removing the sizing agent by heating, then, can replace sand to form a CLSM. Such recycling profit is around 35 USD per ton.

Author Contributions: Conceptualization, J.-H.C., Y.-S.T. and P.-Y.Y.; methodology, Y.-S.T.; software, Y.-S.T.; validation, Y.-S.T. and P.-Y.Y.; formal analysis, J.-H.C. and P.-Y.Y.; data curation, Y.-S.T.; writing—original draft preparation, Y.-S.T. and P.-Y.Y.; writing—review and editing, J.-H.C.; supervision, J.-H.C. All authors have read and agreed to the published version of the manuscript.

Funding: This research received no external funding. 
Data Availability Statement: The data used in this study is a private data set provided by CYUT organization.

Conflicts of Interest: The authors declare no conflict of interest.

\section{References}

1. Farinha, C.B.; de Brito, J.; Veiga, R. Assessment of glass fiber reinforced polymer waste reuse as filler in mortars. J. Clean. Prod. 2019, 210, 1579-1594. [CrossRef]

2. Arczewska, P.; Polak, M.A.; Penlidis, A. Degradation of glass fiber reinforced polymer (GFRP) bars in concrete environment. Constr. Build. Mater. 2021, 293, 123451. [CrossRef]

3. Zhang, Y.; Pontikes, Y.; Lessard, L.; van Vuure, A.W. Recycling and valorization of glass fiber thermoset composite waste by cold incorporation into a sustainable inorganic polymer matrix. Compos. Part B Eng. 2021. [CrossRef]

4. Derby, B. Composite Materials Science and Applications, 2nd ed.; Springer: New York, NY, USA, 2010.

5. Novais, R.M.; Carvalheiras, J.; Seabra, M.P.; Pullar, R.C.; Labrincha, J.A. Effective mechanical reinforcement of inorganic polymers using glass fiber waste. J. Clean. Prod. 2017, 166, 343-349. [CrossRef]

6. Ferdous, W.; Manalo, A.; Siddique, R.; Mendis, P.; Zhuge, Y.; Wong, H.S.; Lokuge, W.; Aravinthan, T.; Schubel, P. Recycling of landfill wastes (tyres, plastics and glass) in construction-A review on global waste generation, performance, application and future opportunities. Resour. Conserv. Recycl. 2021, 173, 105745. [CrossRef]

7. Hemmings, R.T. Process for Converting Waste Glass Fiber into Value Added Products (DOE GO13015-1OMB 0348-0039); Albacem LLC.: Peoria, IL, USA, 2005.

8. Clark, E.; Bleszynski, M.; Valdez, F.; Kumosa, M. Recycling carbon and glass fiber polymer matrix composite waste into cementitious materials. Resour. Conserv. Recycl. 2020, 155, 104659. [CrossRef]

9. Rani, M.; Choudhary, P.; Krishnan, V.; Zafar, S. A review on recycling and reuse methods for carbon fiber/glass fiber composites waste from wind turbine blades. Compos. Part B Eng. 2021, 215, 108768. [CrossRef]

10. Rajak, D.K.; Pagar, D.D.; Menezes, P.L.; Linul, E. Fiber-Reinforced Polymer Composites: Manufacturing, Properties, and Applications. Polymers 2019, 11, 1667. [CrossRef] [PubMed] 